Nordic Concrete Research - Publ. No. NCR 60 - ISSUE 1 / 2019 - Article 3, pp. 31-50

\begin{tabular}{|l|r|}
\hline \multicolumn{1}{|c|}{ S sciendo } & \multicolumn{1}{c|}{$\begin{array}{c}\text { Nordic } \\
\text { Concrete } \\
\text { Federation }\end{array}$} \\
\hline $\begin{array}{l}\text { C) Article authors. This is an open access article distributed } \\
\text { under the Creative Commons Attribution-NonCommercial- } \\
\begin{array}{l}\text { NoDerivs license. (http://creaticecommons.org/licenses/by.nc- } \\
\text { nd/3.0/). }\end{array}\end{array}$ & $\begin{array}{r}\text { ISSN online 2545-2819 } \\
\text { ISSN print } \quad 0800-6377\end{array}$ \\
\hline DOI: $10.2478 /$ ncr-2019-0007 & $\begin{array}{r}\text { Received: March 31, } 2019 \\
\text { Revision received: June 14, 2019 } \\
\text { Accepted: June 18,2019 }\end{array}$ \\
\hline
\end{tabular}

\title{
Use of Concrete for Road Infrastructure: A SWOT Analysis Related to the three Catchwords Sustainability, Industrialisation and Digitalisation
}

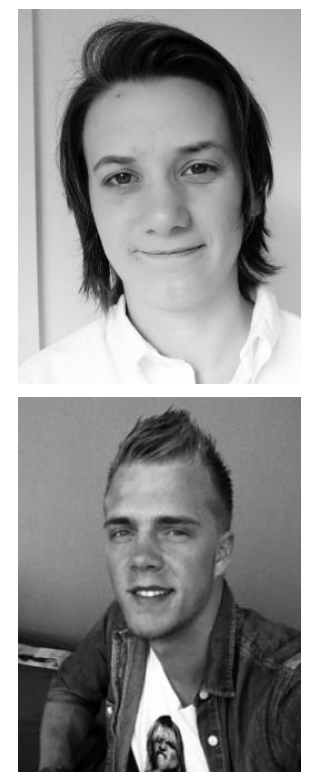

Ingrid Lande Larsen, M.Sc.

PhD Research Fellow, University of Agder

Jon Lilletuns vei 9,

4879 Grimstad

ingrid.larsen@uia.no

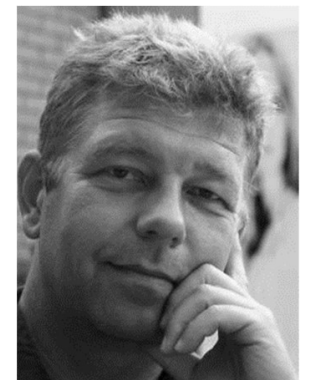

Otto Terjesen, M.Sc.

PhD Research Fellow, University of Agder

Jon Lilletuns vei 9,

4879 Grimstad

otto.terjesen@uia.no

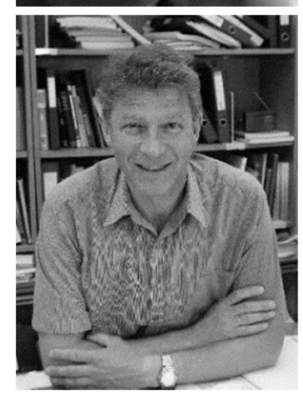

Terje Kanstad, Ph.D.

Professor, Norwegian University of Science and Technology

Richard Birkelands vei 1A,

7491 Trondheim

terje.kanstand@ntnu.no 


\begin{abstract}
This paper aims at identifying the direction for more sustainable development of the use of concrete in road infrastructure in an industrialised context.
\end{abstract}

The increase in the global mean temperature is one of the most severe challenges today. The concrete industry is responsible for significant emissions of greenhouse gases, most attributable to cement production. However, concrete is one of the most important building materials in the world and indispensable for the societal development in countries at all development stages. Thus, the concrete industry needs to take measures for reducing emissions.

This paper investigates possible directions for the development of the concrete industry, to reduce climatic impact and accommodate positive societal growth. The investigation is carried out as a SWOT analysis, focusing on three terms dominating the present discussion on any development within the construction industry; sustainability, industrialisation and digitalisation. The result is a thorough discussion and a set of recommendations for the direction of future research and innovation on sustainable use of concrete in the construction of road infrastructure. The major opportunities and threats are summarised in the conclusions, and future research to be carried out in two of the authors' PhD-projects are described.

Keywords: Concrete infrastructure, Sustainability, Digitalisation, Industrialisation, SWOT analysis

\title{
1. INTRODUCTION
}

In a world striving towards sustainable development, economic, societal and environmental perspectives have to be implemented simultaneously. All these issues are challenging to the construction industry. The development of road infrastructure is fundamental to the growth of the economy and welfare.

The increase in the global mean temperature is currently one of the most severe sustainability issues [1]. According to the Intergovernmental Panel on Climate Change (IPCC), the global mean temperature has increased rapidly during the last 50 years and is projected to rise [2], clearly influenced by anthropogenic emissions of greenhouse gases. The prospects of continued emission are further global warming and long-lasting changes in climate systems, increasing the severe, negative effects for people and ecosystems [2]. In order to limit these climate change risks, substantial reductions in greenhouse gas emissions are required. Consequently, IPCC has established global reduction goals on $\mathrm{CO}_{2}$ emissions for all nations. Norway has committed to reduce the greenhouse gas emissions of at least 40\% compared to 1990 levels within 2030 [3]. Other authoritative sources define different goals and different deadlines for when these goals are to be met. Accommodating different time span requires implementation of different strategies. Some of these strategies might even be conflicting [4].

Concrete is indispensable for the development of countries at all development stages. The annual growth in consumption of concrete in highly developed countries has diminished. However, densely populated countries are still rapidly evolving, consequently experiencing rapid growth in the use of concrete. Hence, the world's demand for concrete is growing. The development of societies and climatic changes lay premises for the development and use of concrete. Three topics 
are presently dominating most discussions on industrial and societal development; i) sustainability, ii) industrialisation and iii) digitalisation. These terms are widely used, and each user tends to define the contents slightly differently.

In this article, a functional definition of the three catchwords is stated, and SWOT analysis is executed for each of them to help identify the direction of sustainable development for the use of concrete in road infrastructure in an industrialised context. The main opportunities and threats are summarised and used as a basis for future research in the first and second authors' $\mathrm{PhD}$-projects.

3.

RESEARCH METHODOLOGY

A SWOT analysis is executed to investigate premises for sustainable growth in the use of concrete in road infrastructure, and to identify research needs. SWOT is an abbreviation for the four terms Strength, Weaknesses, Opportunities and Threats, and is a well-known tool in economic and strategic management. The usage is not equally widespread in the construction industry. However, successful implementation is emerging. Jiang et al. [5] applied a SWOT analysis to study off-site construction in China. Yuan [6] correspondingly investigated successful construction waste management. Both gathered data for the SWOT analysis through interviews or meetings with experts, combined with literature reviews including research, regulations, and government reports $[5,6]$. Inspired by these researchers, we applied a model for research methods, as illustrated in Figure 1. In this study, SWOT analysis is executed on the three topics; i) sustainability, ii) industrialisation and iii) digitalisation.

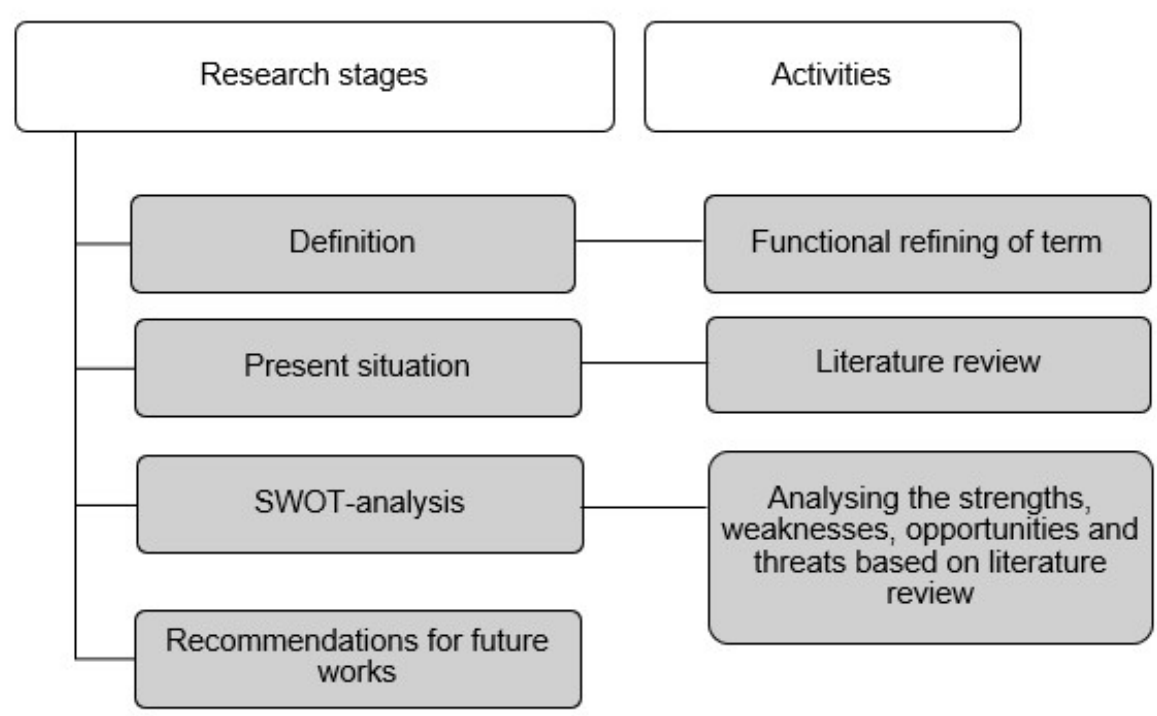

Figure 1-Applied research methodology, similar to Yuan [6]. 


\section{Sustainable use of concrete}

\section{Functional refinement of the term}

Sustainability is a broad term, often defined as "development that meets the needs of the present without compromising the ability of future generations to meet their own needs". This definition origins from Report of the World Commission on Environment and Development: Our Common Future from 1987 [7]. Different professions tend to define sustainability in either economic, societal or environmental terms. All of these are necessary preconditions to support the needs of future generations. In the book Concrete and Sustainability, Jahren and Sui [4] define sustainability as the overlapping field between economy, social development and environment. This definition is applied in the following discussion. However, "environment" is in this paper limited to climate issues only.

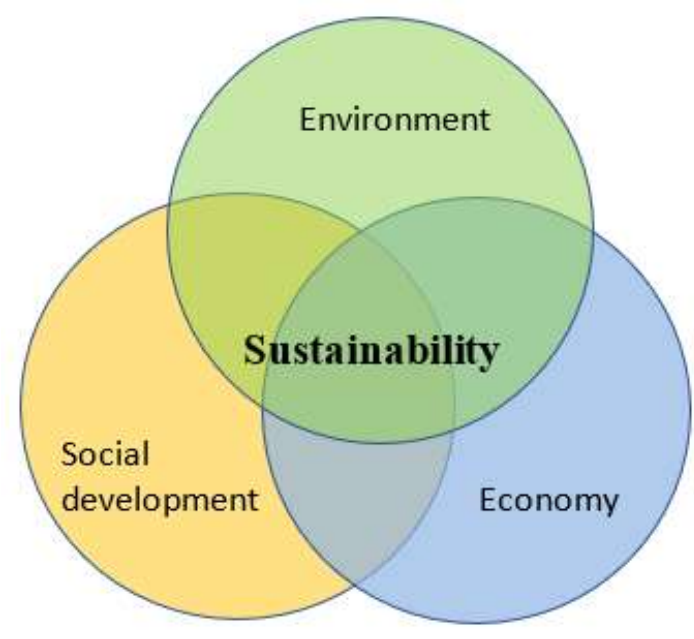

Figure 2 - Sustainable development, according to [4].

\section{Present situation}

According to the European Cement Association CEMBUREAU, the total cement production in the world was 4.65 billion tonnes in 2016 [8]. Anticipating an average world consumption of 300 $\mathrm{kg}$ cement per cubic meter concrete, the present cement production corresponds to almost 2 cubic meters of concrete per capita in the world is built into new structures every year. Scrivener et al. [9] illustrate the consumption of concrete relative to other conventional building materials (Figure 3, left part), according to a report based on the efforts from the UN Environmental Program Sustainable Building and Climate Initiative. Without even arguing on the mechanical and durability properties, price or geographic availability of various materials, it is evident from a pure volume perspective that no other material can fully substitute concrete.

According to Jahren and Sui [4], Asia is responsible for approximately $80 \%$ of the world's cement production. The major part of the growth is due to countries outside China, India and Japan [4], mostly in low-income countries with strong growth in population and economy. In 2017 the world population was 7.6 billion, expected to grow to nearly 10 billion within 2050 [10]. Assuming cement consumption per capita remaining at today's level, the production of cement will have to grow to 6 billion tonnes in 2050, only considering the population growth. This result corresponds to an estimate made by the International Energy Agency [9]. 
Nordic Concrete Research - Publ. No. NCR 60 - ISSUE 1 / 2019 - Article 3, pp. 31-50

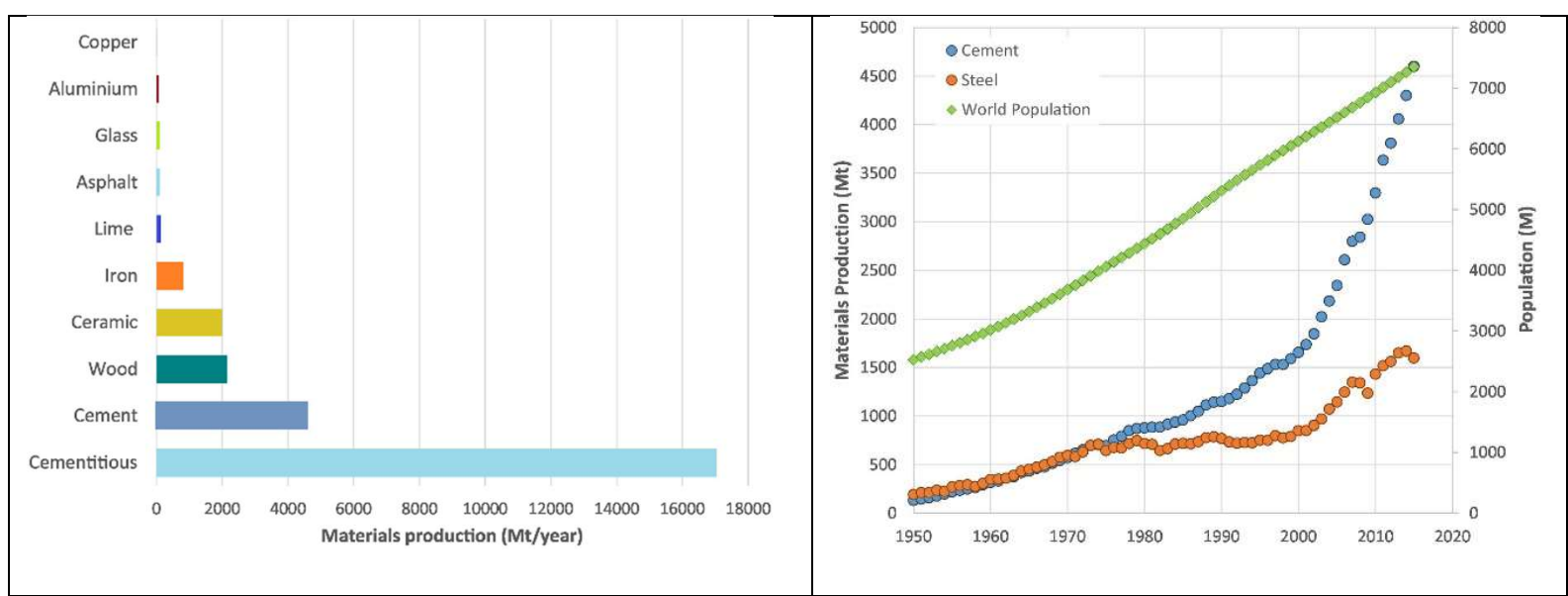

Figure 3 - Left part: Estimated consumption of common materials 2002-2005 [9]. Right part: Correlation on growth in world population and cement production 1950-2015 [9].

The World Bank estimates that around $40 \%$ of the world's population lives in low-income countries and that more than $60 \%$ of those living in slums without access to simple infrastructure like sanitation [9]. To accommodate the needs for a decent level of societal infrastructure for both the existing world population and the expected growth, the above estimate for cement consumption seems conservative. Scrivener et al. [9] showed that while the world population grew by $15 \%$ during the period 2000-2015, the cement production grew by $150 \%$ (Figure 3, right part). This unproportional growth in cement production probably illustrates welfare growth exceeding population growth.

According to CEMBUREAU [8], the cement and concrete industry generated more than 380000 direct jobs within the EU in 2012. Also estimating indirect effects, this number grows to more than 1 million. EU is far more industrialised than most low-income countries, where concrete consumption is expected to grow. Hence, the importance of employment and economic growth is huge.

The social and economic impact stemming from the consumption of concrete seems indispensable, both due to material properties for creating necessary infrastructure and for the role of the related industry to generate personal employment, security and welfare for the citizens. Additionally, the structures being built through the concrete consumption constitute infrastructure and arenas necessary for future growth in industrial and social activities, economy and welfare.

\section{SWOT analysis}

As argued above, cement and concrete are indispensable for sustainable development of society. Consumption will grow substantially, especially in low-industrialised countries. Cementitious materials are favourable for availability, cost-effective and flexible design, simplicity of use, high strength/cost ratio and high durability. However, the concrete industry is responsible for a considerable demand for resources and greenhouse gas emissions. Production of cement is most significant, accountable for approximately $5-7 \%$ of the global anthropogenic $\mathrm{CO}_{2}$ emissions [1113].

A major measure to reduce $\mathrm{CO}_{2}$ emissions would be carbon capture and storage (CCS) or even better than storage; use (CCU). A project on CCS is under development in Norway, including a full-scale pilot on Norcem's factory in Brevik expected to be realised in 2020-21. However, CCS is expensive, and unless disruptive technology is emerging, CCS/CCU is not expected to solve 
the climatic challenges of the cement industry worldwide. This was the origin of a UN initiative to find alternative solutions on $\mathrm{CO}_{2}$ reduction from the use of cementitious materials, recently reported by Scrivener et al. [9]. Mehta [1] proposes three tools for making the concrete industry more sustainable; i) consume less concrete for new structures, ii) consume less cement in concrete mixtures and iii) consume less clinker for making cement. Scrivener et al.'s conclusions are in harmony with Mehta's approach, and this logic is followed in the discussion below. Several measures are essential for global solutions, without being central to development in highly industrialised societies. A fourth tool - spanning wider than just within the cement and concrete industry is related to utilising resources that are waste from other industrial processes (often referred to as by-products) -; iv) circular economy.

\section{i) Consume less concrete for new structures}

Improved durability - reducing the need for replacement of structures - is unarguably an effective mean to reduce consumption of resources in a long-time perspective. The designed service life of infrastructure members such as bridges and tunnels in Norway is 100 years [14, 15]. The designed service life is the period a structure is expected to be in use fulfilling its intended purpose with predicted maintenance, without extensive repairs [14]. Jahren and Sui [4] emphasise that designing structures for enhanced durability has a significant positive effect on emissions when considering long-time span, but might conflict towards short time focus.

Several strategies support durability enhancement. Two of those are careful design of structures to reduce degrading loads (e.g. avoiding surface water accumulation) and careful execution of construction work (e.g. avoiding reinforcement corrosion due to lack of cover). A third measure is careful inspections and maintenance, to stop degradation before it has propagated to a level where replacement is favourable to repair.

A fourth measure - emphasised by Mehta - is using highly durable concrete materials. Ultra High Performance Concrete (UHPC) is an emerging material presently being subject to massive research efforts. In addition to having higher strength than standard concrete, UHPC is also defined by having enhanced durability. This eliminates reinforcement corrosion caused by carbonation or chloride migration $[16,17]$, within any service life expectancy. Pilot projects are being built worldwide, and some early design codes have even been introduced [18, 19]. Using UHPC in the rehabilitation of existing concrete bridges is also investigated by several researchers $[12,20]$. Habert et al. [12] showed that it is possible to lower the impact over the life cycle by using UHPC solutions rather than traditional methods.

Design optimisation offers several strategies to reduce concrete consumption. One is designing structures with flexibility for future changes in use. Another is the optimisation of cross sections. Prefabrication might support this, e.g. by offering slender beams with optimised cross sections, that would not be economically favourable for on-site production. Traditionally, concrete design utilises the lower part of the strength span allowed by design codes such as EN 1992 (EC2) [21]. Traditional use of concrete in structural design has rarely aimed at reducing $\mathrm{CO}_{2}$ emissions. Investigating potential in the exploitation of high strength concrete and concrete having high targeted performance in other areas, might be fruitful.

Utilising the unique mechanical properties and the possible enhanced service-life of UHPC can drastically reduce the material consumption of concrete for some types of structural members [22]. Several studies [23-25] have shown that using high and ultra high performance concrete for construction can give more environmentally friendly solutions. A study aiming at innovation in 
traditional building design, focused on the utilisation of high strength concrete still within the limitation of EC2, in combination with biaxial hollow decks [26]. Potential for $60 \%$ reduction of $\mathrm{CO}_{2}$ and at the same time $20 \%$ reduction of the cost was indicated, utilising today's formal regulations and commercially available products. Scrivener et al. [9] also concluded that using high strength concretes in suitable applications can be more efficient and decrease the total material consumption.

\section{ii) Consume less cement in concrete mixtures}

It is known that the amount of cement used to produce concretes of given strength and workability, varies enormously. Utilising pozzolans or other supplementary cementitious materials (SCM) to partly substitute cement in ready-mix production, is a well-implemented measure to use less cement. A drawback is the extended hardening time. Utilising 56- or 90-days strength instead of 28-days strength in structural design makes it possible to exploit the potential of these concretes [1]. However, this practice is often conflicting with design standards. According to the preliminary version of EC2 (2021), it will be possible to utilise 91-day compressive strength.

Another possibility to use less cement is to minimise the amount of water needed for obtaining the required consistency of fresh concrete. When keeping w/c-ratio constant, reduction of water consequently reduces the amount of cement. Superplasticisers can be utilised to reduce the amount of water required, still maintaining workability [1]. However, this strategy is well utilised in industrialised countries.

Further development to reduce water content is related to the functions of paste in concrete. The primary function is to fill the voids between aggregate particles; to envelope each particle in "glue" to obtain the required strength and durability of hardened concrete. The volume of voids is a function of particle packing. Scrivener et al. [9] claim that packing the particles of aggregate by carefully selecting the dosages of different fractions is an effective measure to reduce water and cement content in concrete. Mehta [1] also mentions the possibilities lying in optimised aggregate size and grading, without in this connection making an issue of the extra resources this would request. A secondary function of the paste in concrete is to reduce friction between aggregate particles to enhance the workability of fresh concrete. This is obtained by adding a surplus of paste exceeding the volume of voids to separate aggregate particles from each other, and hence increasing the consumption of cement. The shape of the particles also rules the friction within aggregates, as the content of flaky shaped particles creates more friction. Consequently, reducing the share of flaky shaped particles reduces the need for paste in the concrete.

Additionally, there is an emerging focus on the effect of small particles in concrete; the fillers. Scrivener et al. [9] claim that "engineering particle size distribution combined with the use of dispersants allow a binder replacement of up to $70 \%$ by inert fillers without the negative effects of dilution." Properties and grading of aggregates vary with location, which might explain variations in cement consumption. The consumption of cement, and hence also the price, can effectively be reduced by increasing focus on the composition of aggregates and the use of fillers. These measures are also location independent.

\section{iii) Consume less clinker for making cement}

Consume less clinker for making cement can be obtained by utilising other cementitious materials for partly substituting Portland clinker [1]. Depending on properties, these materials can be added into the cement production prior to, or after the calcination process - thus ending up as SCMs. Some examples are fly ash, silica fume, ground granulated blast furnace slag, rice husk ash, lime 
filler and several other natural pozzolans $[9,24]$. This is considered to be one of the key strategies to reduce greenhouse gas emissions from concrete production [9] having an effect both on a short time horizon and lifetime perspective [4]. The availability of these materials depends on other productions, as they are often by-products from industrial processes. Some SCMs have shown to mutually affect each other positively. These synergetic mechanisms of ternary and quaternary binder blends are not yet fully investigated. If the particle size distribution and combinations of cement, fillers and SCMs are fully optimised, an average clinker substitution level of above 40\% is realistic worldwide [9].

Often, SCMs have slower strength development than cement clinker, and resistance towards migration develops correspondingly. This slower development might require intermediate measures towards the migration of harmful components into unmatured concrete. Additionally, the availability of SCMs differ locally, and some require costly processing to obtain acceptable quality [9].

\section{iv) Circular economy}

Circular economy is gaining increased attention. The aim is to improve utilisation of resources, decrease waste and improve sustainability. This philosophy has several applications within the concrete industry. The most obvious would be the reuse of structures or elements for other purposes than they were designed for. Use of SCMs stemming from industrial processes to substitute cement is another example.

The construction industry produces large amounts of materials that are presently deposited or used for landfill; some from construction works and demolition of old structures, others from excavation or blasted rock. Xuan et al. [13] suggest one way of making the concrete industry more sustainable by increasing the use of waste from ready-mix concrete plants. Another study showed that it is possible to produce UHPC with reduced cement content [27] by utilising a by-product from the production of gravel. Often, these surplus masses are produced on-site, where aggregate for concrete is required. However, they fail to fulfil quality requirements according to concrete standards. For some materials, the quality requirements can be obtained by simple processing. However, tests also show that it is possible to produce high-quality concrete from aggregates that fail to meet some standardised quality requirements.

The concrete industry is ruled by formal regulations. Severe efforts are put into harmonising standards internationally, to simplify execution and to take advantage of existing competence. The existence of clear, authoritative guidelines are guarantors for quality and safety. However, standardised solutions might prevent innovation. Scrivener et al. [9] emphasise that avoiding the prescriptive regulations in traditional standards and instead allowing for flexibility to exploit local opportunities for raw materials can only be achieved with performance standards specifying properties that must be met (like strength, E-modulus and durability).

The above findings are organised by strength, weaknesses, opportunities and threats (SWOT) and presented in Table 1. 
Table 1 - SWOT sustainable use of concrete

\begin{tabular}{|c|c|}
\hline $\begin{array}{l}\text { Strengths } \\
\text { - The demand is increasing and will remain so } \\
\text { due to population growth. } \\
\text { No material can replace concrete, due to } \\
\text { required volume and availability. } \\
\text { - Several advantages, like the simplicity of use, } \\
\text { local part materials, flexible in design, cost- } \\
\text { effectiveness and durability. }\end{array}$ & $\begin{array}{l}\text { Weaknesses } \\
\text { - Resource demanding locally and globally. } \\
\text { - Causes substantial } \mathrm{CO}_{2} \text {-emissions. } \\
\text { - Conflicting timespan considerations for } \\
\quad \text { varying environmental goals. }\end{array}$ \\
\hline $\begin{array}{l}\text { Opportunities } \\
\text { Reduction of environmental loads through } \\
\text { - Reduced material consumption through } \\
\text { innovative design, prefabrication and use of } \\
\text { HPC and UHPC. } \\
\text { - Clinker reduction by use of SCMs and fillers. } \\
\text { - Cement reduction by optimising grading and } \\
\text { - } \text { shape of aggregate particles. } \\
\text { Utilising potential in extended maturity } \\
\text { considerations ( } 91 \text { days hardening time, and } \\
\text { innovative hardening technology). } \\
\text { - Increase the use of waste and recycled } \\
\text { materials. } \\
\text { - Enhancement of durability. } \\
\text { CCS/CCU. }\end{array}$ & $\begin{array}{l}\text { Threats } \\
\text { - } \quad \text { Climatic changes. } \\
\text { - Resource demanding. } \\
\text { - } \quad \text { Rigid regulations. } \\
\text { - Availability of SCMs. }\end{array}$ \\
\hline
\end{tabular}

\section{Industrialisation of the construction process}

\section{Functional refinement of the term}

The term "industrialisation" is traditionally used to characterise the transition of economies from being dominated by agriculture, towards being dominated by manufacturing. Development of new technology, including the steam engine, was the vital driving force for the European transition. The term is still frequently used even in highly developed economies, now to describe the transition of industrial sectors away from craftsmanship and one-of-a-kind solutions, towards standardised and automated production. The gaining is efficiency; a higher volume of production per time and at a lower cost. Once again, new technology is a major driving force. However, the organisation of processes and data to promote human interaction is considered equally important.

\section{The present situation}

The construction industry is still dominated by one-of-a-kind design and low level of automation in management, design and production. Although changes as increased use of innovative formwork technology, self-compacting concrete, fibre reinforcement, grinding- and surface treatment machinery, and sprayed concrete robots are emerging, it is widely accepted that construction lags behind manufacturing industry on productivity. The Norwegian construction industry and the government have established a joint effort to improve productivity and sustainability, named Bygg21. In a recent report from Bygg21, the following definition is given: "Industrialising construction projects is to plan and execute processes; maximising repeated use of standardised solutions, industrial methods and digital tools" [28].

The well-known "Lean Construction" (LC) philosophy, adapted from Toyota's "Lean Production", has inspired this definition. Most major contractors have been struggling to 
implement LC for many years already, often adopting company-specific names like Veidekke's "involverende planlegging" (participative planning). LC-implementation has often originated onsite to manage logistics and fabrication, but efforts are now spanning the entire process from planning and design, throughout deliverances that support operation and maintenance. Several "models" or "schools" have been developed to support these processes; like "Integrated Project Delivery" (IPD) and "Virtual Design and Construction" (VDC).

\section{SWOT analysis}

Three basic principles central to LC are: i) to improve flow in processes, ii) to reduce waste and iii) to continuously learn from experiences. These three principles are used for facilitating the SWOT analysis below.

\section{i) Improve flow in processes}

The most important "flow" in construction processes, is the flow of information relevant for each actor to execute his/her part as efficient as possible. All actors in the construction process must be involved early enough to influence actions laying premises for their own deliverance. All must also have access to correct and required information prior to executing any action, and uncertainty must be adequately handled. IPD is developed as a method utilising early involvement to focus on producing maximum value for the customer through building alliances between all people and "systems" vital for production, avoiding individual stakeholders to sub-optimise own gaining.

Though theoretical approaches to LC emphasise manual tools like "PostIt-technique", the industry soon called for computer-based LC implementations, due to the amount of information to be handled and the number of actions necessary for keeping the system updated [29]. IPD clearly defines seven sequences in a construction project, identifying vital actors in each sequence. This clear structure facilitates the use of digital solutions. Building Information Model/Modelling (BIM) is emphasized as "one of the most powerful tools supporting IPD" [30]. This is argued by BIM being able to combine all information and support all phases in a construction process, from design through the entire life-span. This is correctly the idea of BIM. However, there are still some shortcomings in the present use of BIM. Some of these are discussed in the section "Digitalisation" further down in this paper.

Another important "flow" in construction processes is the fabrication. Traditional thresholds include uncertainty; related to logistics, lack of drawings or staffing, unwanted events, etc. Prefabrication might be a strategy to reduce uncertainty. A state-of-the-art report by the Fédération Internationale du Béton (fib) from 2004 [31] reports that there are significant differences in the development and application of precast bridges in various countries. In the report, it is claimed that "Especially in the Scandinavian countries, there are few precast bridges, although the climatic conditions would logically incite to an opposite attitude". According to an investigation amongst practitioners on the use of precast bridge elements [32], there seems to be a widespread opinion that precast bridges are more prone to damage due to degradation mechanisms. These problems are recognised for bridges dated before 1990. However, in an investigation based on the NPRA database "Brutus", it was found that this is not correct - at least for bridges designed according to standards dated after 1990 [33].

Figure 4 (left part) shows the results of an investigation mapping the bridges related to four-lane national highways in the south of Norway [32]. As shown in the figure, there is a tendency that highway bridges are limited to a low number of typical lengths, clearly indicating a large potential for standardisation. NPRA has recently initiated two projects to use more prefabricated elements 
in road construction. One of them has resulted in standardised solutions for prefabricated concrete culverts. The other project aims to develop new pre-accepted precast bridge solutions utilising up to 40 meter long beams [34].

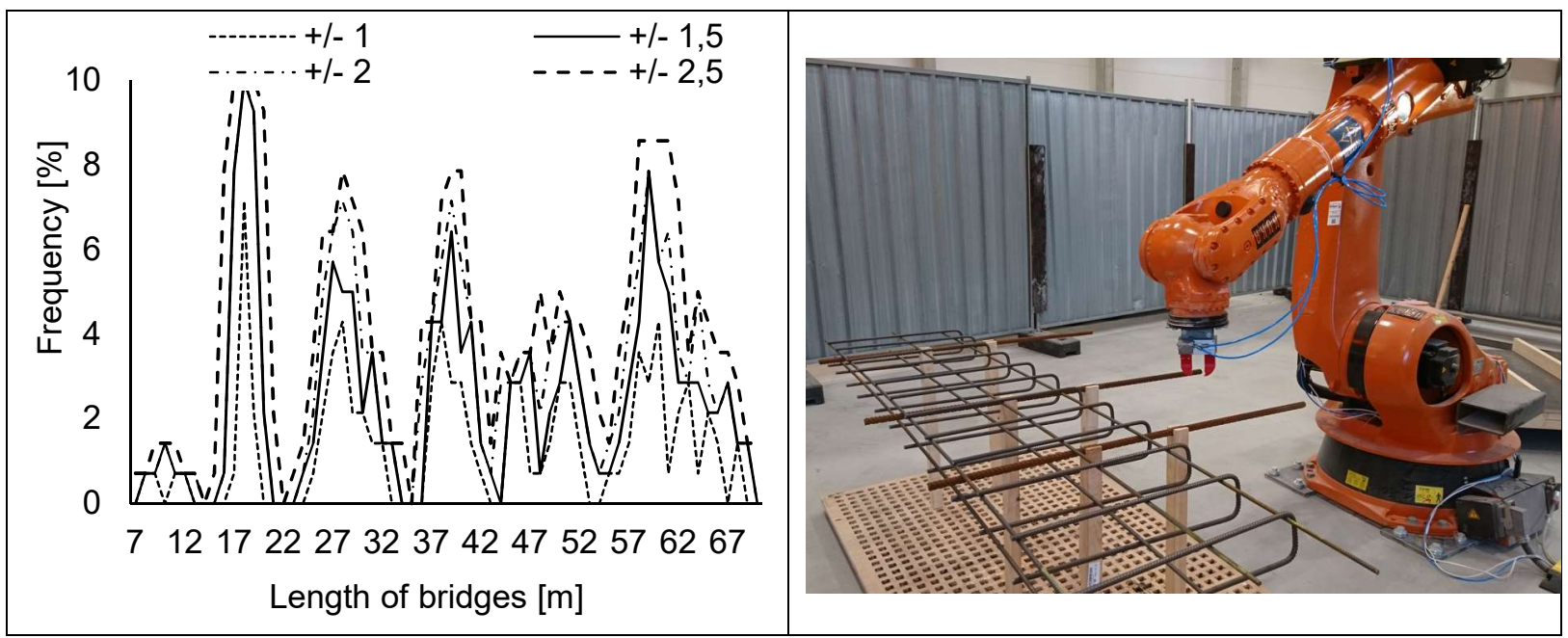

Figure 4 - Left part: Frequency of length of bridges on four-lane national highways in the south of Norway (a total of 140 bridges were included) [32].

Right part: Robotised placement and welding of prefabricated reinforcement.

Photo: Rebartek-Maximilian Trommer.

According to [32], some interviewed experts highlighted that there are challenges for precast bridges related to requirements in the regulation for bridge constructions by NPRA [14]. The Norwegian topography can also limit the use of straight precast elements. Transport on Norwegian roads can limit the span length both due to regulations and due to the road geometry (roundabouts define the maximum bridge lengths). Additionally, prefabricated (standard) elements are straight, limiting the road geometry, horizontal and vertical curvature, transverse inclination and inclining abutments. However, most agreed on the benefits of prefabrication regarding Health, Safety and Environment (HSE). Higher production speed, improved quality, reduction of traffic interrupts and potential reduction of production cost were other benefits emphasized in the interviews. These are major indicators of higher efficiency.

\section{ii) Reduce waste}

Improving flow inevitably leads to reduction of waste, as time is saved for involved personnel and equipment. Time is valuable both to business (personnel and equipment) and to the social economy (e.g. reducing traffic interruption).

Waste can also be reduced by implementing new technology like automated production of reinforcement cages (Figure 4, right part). In addition to the reduction of production time and material consumption it opens for more advanced design, e.g. by welding the minimum required the amount of reinforcement, omitting lap joints and reinforcement design optimised for production rather than structural needs. VDC is another process model heavily focusing on BIM and visualisation; including 3D models and further dimensions (time, cost, progress, risks, etc.). Once again, the primary driving force is to secure interaction and information access through organisation and the use of technology creating a work zone where all construction activities take place. 
Standardisation is expected to promote industrialisation in road construction by reducing the number of alternative solutions, e.g. for fixation of railings. Reduction of the alternative solutions increases reuse of formwork, scaffolding and production techniques. Learning by repeated doing is a consequence of standardisation of production, resulting in reduction of process time, increased predictability and reduction of errors. Also, the reduction of work hours related to design processes and quality control are positive outcomes.

Standardisation inevitably leads to repetitive use of structural solutions, which might be perceived as aesthetically monotonous, limiting architectural expression. Traditionally, aesthetics is considered vital for Norwegian road infrastructure governed by an NPRA report [35]. Another drawback is that standardisation may act to conserve today's solutions. The regime of standardisation offered by today's formal regulations is frequently criticised for being conservative and counteracting new solutions and cost reductions. The urge to standardise for promoting leaner production today might prevent innovation and be a threshold to cost-efficient changes in the future. Additionally, the basic purpose is to ensure solutions that have proven their durability in practice. If opening the rigidity of standards to promote innovation, measures must be taken to make sure that the durability aspect is still attended.

\section{iii) Continuously learning from experiences}

Seen in the light of hindsight, some parts of a construction process could always have been improved. Individuals often claim to learn from experiences, however organisations like companies are known to struggle to avoid repeating mistakes. Explicit measures for organisations to learn from experiences calls for systematic registration, analysis, alternative investigation, storing and active education. Formal initiatives, processes and systems to promote this kind of organisational learning, are not always well developed. Digitalisation provides powerful tools supporting this development, but still the organisation of humans and processes is needed. One obvious reason why this is still often lacking is that these processes are time-consuming. However, the overall goal is to reduce time consumption by learning systematically from experiences.

Another measure to promote learning is the use of formerly approved solutions and practices. This might be formal standardisation through legal regulations and design codes, or restrictions given by building client (like the above-mentioned restrictions for fixation of railings along highways). However, it might also be the reuse of former design, proven to be successful. Once again, the use of digital solutions like BIM supports this kind of "standardisation" through easy access and reuse. However, also this kind of standardisation might prevent innovation. 
Table 2 - SWOT industrialisation of the construction process

\begin{tabular}{|c|c|}
\hline $\begin{array}{l}\text { Strengths } \\
\text { - Improved productivity by reducing the time } \\
\text { - } \quad \text { for design and production. } \\
\text { - } \quad \text { Reduce climate impact (by reducing waste). }\end{array}$ & $\begin{array}{l}\text { Weaknesses } \\
\text { - Depending on successful implementation of } \\
\text { interaction between numerous actors. }\end{array}$ \\
\hline $\begin{array}{l}\text { Opportunities } \\
\text { - Early involvement improves the possibility to } \\
\text { influence at early stages, avoiding changes at } \\
\text { later stages when the cost of changes rises. } \\
\text { - Correct information required for prerequisite } \\
\text { available for all - at any time. } \\
\text { Consequences of choices understood through } \\
\text { analysis including all existing prerequisites, } \\
\text { and easily available through visualisation. } \\
\text { Advanced/automated production methods } \\
\text { open for design optimised for structural } \\
\text { performance rather than for easy manual } \\
\text { production. } \\
\text { Standardisation allows for reuse of design, } \\
\text { equipment and production techniques. } \\
\text { Prefabrication allows for cost reduction, } \\
\text { sustainable solutions and improvements on } \\
\text { HSE. } \\
\text { Improved quality through systems for } \\
\text { continuously learning. }\end{array}$ & $\begin{array}{l}\text { Threats } \\
\text { - } \quad \text { Aesthetics - promotes monotony. } \\
\text { - Standard prefabricated elements limit road } \\
\text { geometry and adaptation to terrain. } \\
\text { - } \quad \text { Complicated and demanding handling } \\
\quad \text { processes (lifting, transport and assembly). }\end{array}$ \\
\hline
\end{tabular}

\subsection{Digitalisation of construction and management processes}

\section{Functional refinement of the term}

Digitalisation is the process of using digital methods to achieve results that would not be available without these methods. The enablers are high capacity for accessing, storing, processing and presenting data. In this paper, digitalisation refers to digital information of the structure that is applied in all stages throughout the life cycle of the structure, from design until the end of service life. Digital information in the form of models including metadata may be used at the design stage, for structural analysis and dimensioning, for construction at the building site, for operation, maintenance and management and finally for demolishing, recycling and deposition of waste materials at the end of service life.

\section{Present situation}

There is an emerging interest in the opportunities related to a more digitalised construction industry. The most used development within digitalisation is BIM. By using BIM, it is possible to replace structural drawings with virtual, 3-dimensional digital models of the structure and construction site, and assign more information to the different parts than just the geometry [36]. In addition to the description of the structure and the applied materials, this may include information needed for technical and quality control, and extraction of quantities necessary for pricing. Digitalisation and BIM-models can be used throughout the life cycle of a structure. However, presently the information is often modelled in different ways and by various software tools and platforms from phase to phase, which is a serious hindrance for future development. 
According to Azhar [37], BIM can be used for 3-D visualisation, fabrication of drawings, estimation of cost, automatic extraction and updates of material quantities, construction sequencing (coordinate material ordering, fabrication, and delivery schedules for all building components), conflict situations, and collision detection, to mention some. The same author also mentions that BIM may give benefits in terms of faster and more effective processes, better design (as the design of the buildings can easily be analysed and changed in the digital model), control of the lifetime costs and environmental data, and improved production quality. It is possible to achieve substantial reductions in time consumption related to generating cost estimates and utilise lifecycle data for facility management. More recently there has been increased interest in using BIM to achieve more sustainable solutions by including EPDs (Environmental Product Declaration) in the BIM-model and carry out optimum design [36].

An important part of digitalisation in the construction industry is to use modelling tools and software for structural analysis and dimensioning. Direct application of BIM and the growing sophistication of computer programs, increasing computer capacity and decreasing costs, give great possibilities for better design. Table 3 presents today's practice and two possible future scenarios for structural analyses and design, which both may facilitate more efficient material use and therefore more sustainable solutions.

Table 3 The structural design process

\begin{tabular}{|c|c|c|c|c|}
\hline Solution & Date & Drawings/Design & Structural Analysis & Dimensioning/Design \\
\hline I & Today & $\begin{array}{l}\text { Drawings } \\
\text { or BIM }\end{array}$ & $\begin{array}{l}\text { Linear elastic methods, Finite } \\
\text { Element Analysis (FEA) } \\
\text { occasionally. } \\
\text { Supported by human } \\
\text { competence and special } \\
\text { purpose program accounting } \\
\text { for cracking, creep, shrinkage, } \\
\text { relaxation and temperature } \\
\text { effects, and construction } \\
\text { history. } \\
\text { Nonlinear analysis rarely used } \\
\text { in practice. }\end{array}$ & $\begin{array}{l}\text { Manually in critical } \\
\text { sections, often using } \\
\text { special purpose } \\
\text { programs. }\end{array}$ \\
\hline II & $\begin{array}{c}\text { Future } \\
\text { scenario, } \\
\text { alt I }\end{array}$ & BIM & $\begin{array}{l}\text { Linear elastic FEA based on } \\
\text { the BIM, occasionally } \\
\text { nonlinear and time-dependent. } \\
\text { Modification of linear FEA to } \\
\text { account for cracking, creep, } \\
\text { shrinkage, relaxation and } \\
\text { temperature effects, and } \\
\text { construction history. }\end{array}$ & $\begin{array}{l}\text { Computerised checks of } \\
\text { all sections. }\end{array}$ \\
\hline III & $\begin{array}{l}\text { Future } \\
\text { scenario, } \\
\text { alt II }\end{array}$ & BIM & \multicolumn{2}{|c|}{$\begin{array}{l}\text { Numerical simulation of structural behaviour based on } \\
\text { BIM-model. } \\
\text { Nonlinearities and time-dependent behaviour well } \\
\text { accounted for. } \\
\text { Probabilistic safety-formats. } \\
\text { Structural analysis and dimensioning fully integrated. }\end{array}$} \\
\hline
\end{tabular}


In today's structural design, it is most common that the design of each structural member is done manually in critical sections using special purpose programs. This is time-consuming, and in a market with great competition and economy focus for both designers and contractors, the approach does not always give the optimal solutions and sustainable design.

Compared to today's practice, future scenario I will utilise BIM to make more accurate linear finite element analysis (FEA) of structural systems. Still, care must be taken to distribute stress concentrations, account for time-dependent effects, and in some cases also nonlinear behaviour. This, together with computerised design of all sections in a member, may contribute to more optimal and sustainable solutions. For instance, industrialising the process of prefabricating beams by placing the exact amount of shear reinforcement required by the design code, precisely fixed in position by robots. Hence, industrialising open for flexible production by standardising processes, not products.

Future scenario II assumes frequent use of advanced numerical simulations of the structural behaviour based on the BIM. The preferred method will be Non-linear Finite Element Analysis (NLFEA), including accurate material models. These tasks are challenging and require development of guidelines and regulations to be able to achieve the right structural safety concerning design resistance and robustness, and quality control of the results. NLFEA is used already today, but only in special cases, e.g. for existing structures (remaining/rest-capacity), or when there has been a structural collapse (accident) and investigations to explore the causes are required.

To fully utilise the advancement in digitalisation, to achieve future scenario II, should be one goal to achieve more sustainable solutions but, as mentioned above, further research and development of regulations and guidelines are required.

\section{SWOT analysis}

As illustrated in Figure 5, digitalisation may facilitate communication, information sharing, innovative thinking, design adjustments and construction planning. The different sub-processes work together towards a better and sustainable design.

First sub-process, denoted building opportunities (Gear 1), is constantly moving and must be checked with preliminary and advanced models to obtain the best design. This sub-process also requires feedback from the other sub-processes to improve. If one process works alone and does not communicate, it will hinder the abilities for the other sub-processes to work together.

The authors agree with the statement from Azhar [37] that BIM contributes to a better design, but the authors would like to address this broad term. Among the conclusion for a better design, one is that the building proposals can be rigorously analysed, and simulations performed quickly. 
Nordic Concrete Research - Publ. No. NCR 60 - ISSUE 1 / 2019 - Article 3, pp. 31-50

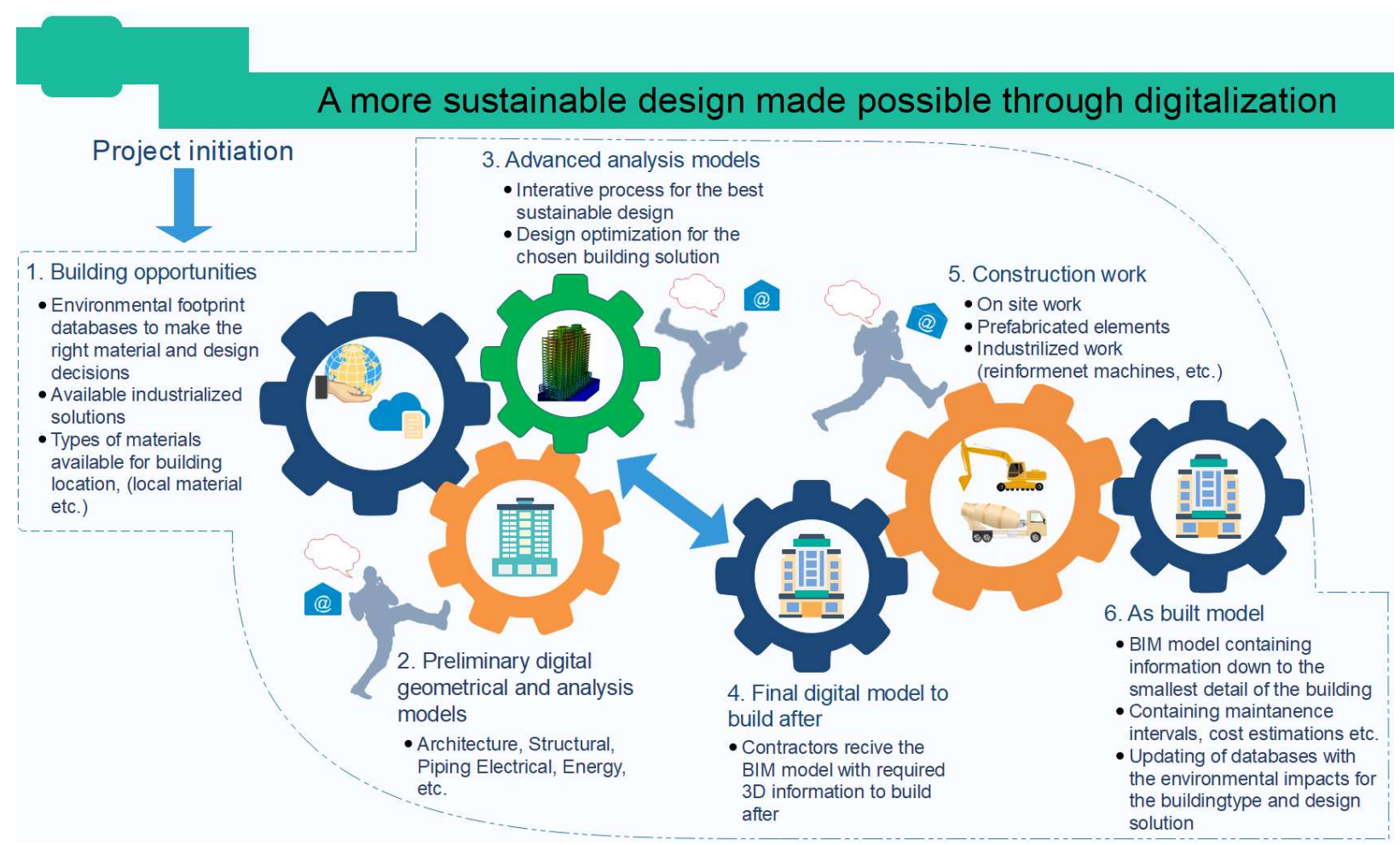

Figure 5 - A more sustainable design made possible through digitalisation (own design of illustration).

A risk when using more advanced software is that complex structures may become too simple to handle in the software's environment. In worst-case, this can lead to serious faults, and also structural failures with large consequences. Therefore, it is of vital importance that engineers understand and maintain competence within their field. Some of the advanced structural analysis programs now available for the industry were previously only available in the academic environments.

Table 4 shows the results from the SWOT analysis in digitalisation of construction and management processes.

Table 4-SWOT Digitalisation of construction and management processes

\begin{tabular}{|c|c|}
\hline $\begin{array}{l}\text { Strengths } \\
\text { - } \quad \text { Faster and more effective processes. } \\
\text { - } \quad \text { More efficient design process and } \\
\text { better quality of the design. } \\
\text { - } \quad \text { Faster and more correct cost estimates. } \\
\text { More accurate geometry and material } \\
\text { modelling for structural analysis. } \\
\text { - More accurate descriptions of the } \\
\text { construction history. }\end{array}$ & $\begin{array}{l}\text { Weaknesses } \\
\text { - Information may be modelled in different ways and } \\
\text { using different software tools and platforms from } \\
\text { phase to phase. } \\
\text { - The computer programs may use different theory } \\
\text { and algorithms than those known to the designer, } \\
\text { which may lead to misunderstandings and faults. } \\
\text { Too large amount of information creates } \\
\text { unnecessary complexity. }\end{array}$ \\
\hline
\end{tabular}




\begin{tabular}{|c|c|}
\hline $\begin{array}{l}\text { Opportunities } \\
\text { - More efficient (economic and } \\
\text { sustainable) use of materials. } \\
\text { - Interaction of BIM and LCA- } \\
\text { software/EPDs. } \\
\text { - More optimal design (easier to improve } \\
\text { the design of a structure). }\end{array}$ & $\begin{array}{l}\text { Threats } \\
\text { - Changes in data-formats and platforms over time. } \\
\text { - Robustness of systems (data storage, hacking, etc.). } \\
\text { - Loss of competence due to phasing out valuable } \\
\text { computer programs. } \\
\text { - Lack of understanding of how the structural } \\
\text { systems work - may lead to possible faults. } \\
\text { - Import of geometrical 3D models for structural } \\
\text { analysis- possibly wrong connections between } \\
\text { elements due to different formats. } \\
\text { - Too much information in the models related to the } \\
\text { necessary task at hand. }\end{array}$ \\
\hline
\end{tabular}

\section{5.}

\section{DISCUSSION}

The aim of this paper is to identify and discuss directions for more sustainable development of the use of concrete for road infrastructure, in an industrialised context. The term "sustainable" is defined to embrace not only environmental issues, however also the economy and social development. Hence, issues regarding HSE and productivity are included. The term "industrialised context" reflects that the discussion regards highly industrialised societies, where advancements in digitalisation and automation are natural traces of development.

Substantial growth in the use of concrete is inevitable. Consequently, measures must be taken to avoid a corresponding growth in $\mathrm{CO}_{2}$ emissions, and to reduce the anthropogenic influence on climate change. Future solutions might involve CCS/CCU, however widespread use of these solutions requires disruptive technology that substantially reduces cost. Hence, CCS/CCU is not further discussed in this article.

The three terms sustainability (in a threefold understanding), industrialisation and digitalisation are separately discussed in SWOT analysis above. No cross-disciplinary conflicts have been identified. On the contrary, synergies are described, and simultaneous utilisation of the three considerations is necessary for realising the full potential in each. A fundamental approach to reduce the use of natural resources, emissions, time and money, is to secure flow in all processes. Flow is pursued by taking all preconditions into account in all processes and choices, including design and production. This calls for sharing information and evaluating each choice real-time, enlightened by all relevant information in the project.

Concepts like "flow", "early involvement" and "sharing information" are all vital in different approaches towards industrialisation, e.g. LC, IPD and VDC. The use of digital methods is another important measure in industrialisation; to achieve results that would not be available without these methods. Hence, further industrialisation requires both organisation of processes and the use of digital methods. Digitalisation on the other hand, will only produce gaining if all relevant information is available. Hence digitalisation requires industrialisation.

\section{6.}

\section{CONCLUSIONS AND RECOMMENDATIONS FOR FUTURE WORK}

The paper considers the three frequently used catchwords; sustainability, industrialisation and digitalisation, and gives a functional refinement of them related to their application within the 
construction industry. As a contribution towards more sustainable solutions within the road infrastructure a SWOT analysis is carried for each term. Several opportunities for sustainable development of the use of concrete have been identified. A prerequisite for taking advantages of these opportunities is that processes for further industrialisation and digitalisation are carefully implemented. Some of these identified opportunities are:

- More efficient use of materials through innovative design, utilisation of advanced and automated production, prefabrication and investigation into smart use of HPC/UHPC.

- More optimal design made possible by early involvement of stakeholders, the interaction of BIM and LCA software, and digital visualisation, allowing for better informed decision processes.

- Improved quality in processes, decisions and products, supported by operational systems for continuous learning; including both explicit actions and knowledge tacit in the reuse and standardisation of solutions.

Several important threats to the sustainable development of road infrastructure have also been identified:

- The main threats towards future sustainable development of the concrete infrastructure are the lack of natural resources, too rigid regulations and availability of SCMs.

- Concerning industrialisation, a threat to be avoided is making solutions that are rational when implemented but may act preservative in the longer run, preventing future innovations.

- Related to digitalisation the major threats are due to changes in data-formats and platforms over time, the robustness of systems (data storage, hacking, etc.), loss of competence due to phasing out valuable computer programs, and finally lack of understanding of how the structural systems work - which may lead to possible faults.

The paper is a part of two ongoing PhD-projects, and the findings in this paper will be followed up. One of these will focus on the development of production of Ultra High Performance Concrete (UHPC) from local constituents and investigate the structural behaviour of this material. The other one will study industrialised sustainable concrete bridges in Service Limit State (SLS). The objective is to improve structural analysis and design of concrete bridges in SLS that are adapted to new sustainability-requirements, industrialisation and digitalisation.

\section{ACKNOWLEDGEMENTS}

Two funding bodies supported this work: The Research Council of Norway (NFR) and Sørlandets Kompetansefond, through the project More Efficient and Environmental friendly Road Construction (MEERC).

\section{REFERENCES}

1. Mehta P K, "Global concrete industry sustainability," Concrete international, vol. 31, no. 2, pp. 45-48, 2009.

2. Pachauri R and Meyer L, "Climate change 2014 Synthesis Report-Summary for Policymakers," ed: Intergovernmental Panel on Climate Change (IPCC), 2014. 
3. Samferdselsdepartement, "Meld. St. 33 Nasjonal Transportplan 2018-2029 (in Norwegian) (National Transport Plan 2018-2029)," Oslo, Norway2017.

4. Jahren P and Sui T, Concrete and sustainability. CRC Press, 2013.

5. Jiang R, Mao C, Hou L, Wu C, and Tan J, "A SWOT analysis for promoting off-site construction under the backdrop of China's new urbanisation," Journal of Cleaner Production, vol. 173, pp. 225-234, 2018/02/01/ 2018.

6. Yuan H, "A SWOT analysis of successful construction waste management," Journal of Cleaner Production, vol. 39, pp. 1-8, 2013/01/01/2013.

7. Brundtland G H, Our common future, Oxford: Oxford University Press, 1987. [Online]. Available.

8. CEMBUREAU The European Cement Association. (2016, 17.03). Key figures. Available: https://cembureau.eu/cement-101/key-facts-figures/

9. Scrivener K L, John V M, and Gartner E M, "Eco-efficient cements: Potential economically viable solutions for a low-CO2 cement-based materials industry," Cement and Concrete Research, vol. 114, pp. 2-26, 2018/12/01/ 2018.

10. United Nations. (2017, 22.03). World Population Prospects: The 2017 Revision. Available: $\quad$ https://www.un.org/development/desa/publications/world-populationprospects-the-2017-revision.html

11. Benhelal E, Zahedi G, Shamsaei E, and Bahadori A, "Global strategies and potentials to curb CO2 emissions in cement industry," Journal of Cleaner Production, vol. 51, pp. 142$161,2013 / 07 / 15 / 2013$.

12. Habert G, Denarié E, Šajna A, and Rossi P, "Lowering the global warming impact of bridge rehabilitations by using Ultra High Performance Fibre Reinforced Concretes," Cement and Concrete Composites, vol. 38, pp. 1-11, 2013/04/01/ 2013.

13. Xuan D, Poon C S, and Zheng W, "Management and sustainable utilization of processing wastes from ready-mixed concrete plants in construction: A review," Resources, Conservation and Recycling, vol. 136, pp. 238-247, 2018/09/01/ 2018.

14. Norwegian Public Road Administration, Håndbok N400 Bruprosjektering (in Norwegian) (Maunal N400 Bridge design). Oslo: Directorate of Public Roads, 2015.

15. Norwegian Public Road Administration, Håndbok N500 Vegtunneler (in Norwegian) (Manual N500 Road Tunnel design). Oslo: Directorate of Public Roads, 2016.

16. Russell H G and Graybeal B A, "Ultra-high performance concrete: A state-of-the-art report for the bridge community," 2013.

17. Thorstensen R, Larsen I, Heimdal A, and Hansen H, "LCC and carbon footprint of bridge made from locally produced UHPC, compared to standard concrete," in Proceedings of HiPerMat 2016 4th International Symposium on Ultra-High Performance Concrete and High Performance Materials, 2016.

18. National addition to Eurocode 2-Design of concrete structures: Specific rules for ultrahigh performance fiber-reinforced concrete (UHPFRC), NF P18-710, 2016.

19. Recommendation: Ultra High Fibre Reinforced Cement-Based composites (UHPFRC): Construction material, dimensioning and application, SIA 2052, 2016.

20. Brühwiler E, "Structural UHPFRC": Welcome to the post-concrete era," in First International Interactive Symposium on UHPC, 2016.

21. Eurocode 2: design of concrete structures-part 1-1: general rules and rules for buildings, EN 1992-1-1:2004, 2004.

22. Randl N, Steiner T, Ofner S, Baumgartner E, and Mészöly T, "Development of UHPC mixtures from an ecological point of view," Construction and Building Materials, vol. 67, pp. 373-378, 2014/09/30/2014. 
23. Habert G, Arribe D, Dehove T, Espinasse L, and Le Roy R, "Reducing environmental impact by increasing the strength of concrete: quantification of the improvement to concrete bridges," Journal of Cleaner Production, vol. 35, pp. 250-262, 2012/11/01/ 2012.

24. Liew K M, Sojobi A O, and Zhang L W, "Green concrete: Prospects and challenges," Construction and Building Materials, vol. 156, pp. 1063-1095, 2017/12/15/2017.

25. Larsen I L, Aasbakken I G, O'Born R, Vertes K, and Thorstensen R T, "Determining the Environmental Benefits of Ultra High Performance Concrete as a Bridge Construction Material," in IOP Conference Series: Materials Science and Engineering, 2017, vol. 245, no. 5, p. 052096: IOP Publishing.

26. Fidjestol P and Thorstensen R T, "Improving sustainability of concrete construction - the role of high strength high performance concrete," presented at the 37 th Conference on Our World in Concrete and Structures, Singapore, 2012.

27. Larsen I L, Thorstensen R T, and Vertes K, "Lowering environmental impact from UHPC, utilizing industrial by-products," in 12th fib International PhD-Symposium in Civil Engineering, Prague, 2018, pp. 93 - 101: Federation internationale du beton (fib).

28. Bygg21, "Tenk nytt - bruk kjente løsninger (in Norwegian) (Think New - Use Known Solutions)," 2019, Available: https://www.bygg21.no/rapporter-og-veiledere/tenk-nyttbruk-kjente-losninger/.

29. Thorstensen R T, Kalsaas B T, Skaar J, and Jensen S, "Last planner system innovation efforts on requirements for digital management system," in Annual conference of the international group for lean construction, 2013, vol. 21.

30. The American Institute of Architects (AIA National \& AIA California Council), "Integrated Project Delivery: A guide," 2007.

31. Fédération internationale du béton (fib), Precast Concrete Bridges: State-of-the-art report. International Federation for Structural Concrete (fib), 2004.

32. Heimdal A, Larsen I L, and Norheim T, "Standardisering av brokonstruksjoner for nasjonale hovedveier (in Norwegian) (Standardization of bridge structures for national highways)," Engineering science, University of Agder, Grimstad, 2017.

33. Bårseth $\mathrm{E}$ and Birkeland $\mathrm{K}$, "Bestandighet og holdninger til flerspenns prefabrikkerte brokonstruksjoner (in Norwegian) (Durability and attitudes towards multi-span prefabricated bridge structures)," BSc thesis, University of Agder, 2018.

34. Persson S, "«Brubjelkeprosjektet» (in Norwegian) ("The bridge beam project")," presented at the Brukonferansen 2017, Oslo 2017. Available: https://www.vegvesen.no/_attachment/2069373/binary/1218553?fast_title=Betongeleme nter.+Stian+Persson $+\% 28 \overline{5}+\mathrm{MB} \% 29 . \mathrm{pdf}$

35. Amundsen I, "Vegen i landskapet, om vakre veger (in Norwegian) (The road in the landscape, about beautiful roads)," in "Norwegian Public Roads Administration reports," No. 300, 2014.

36. Sandvik C and Fougner F, "BIM as a tool for sustainable design," in The International Federation for Structural Concrete 5th International fib Congress, Better - Smarter Stronger, 7 - 11 October 2018, Melbourne, Australia, 2018, pp. 786-791: fib (Fédération internationale du béton).

37. Azhar S, "Building Information Modeling (BIM): Trends, Benefits, Risks, and Challenges for the AEC Industry," Leadership and Management in Engineering, vol. 11, no. 3, pp. 241-252, 2011. 